space) is well fitted to bridge over a discontinuity, by the introduction of an extra copy of space in which the discontinuity is filled up in some suitable way.

The success, however partial, which has attended the quest for mathematical functions that express more and more complicated physical relationships, tends to strengthen our faith in some deep-lying correspondence between the world of nature and the world of the pure intellect. It remains for mathematicians and physicists to discover new winding lines and open doors.

\title{
MATHEMATICAL APPOINTMENTS IN COLLEGES AND UNIVERSITIES.
}

BY PROFESSOR E. J. WILCZYYNSKI.

AT the meeting of the Chicago Section held January 2, 1909, a committee was appointed for the purpose of investigating the possibility of improving the character of mathematical appointments in our colleges and universities. I submitted for the consideration of the members of the committee an adaption of the Italian system which appeared to me to be applicable to American conditions. My views were not shared by the other members of the committee, and our official report has been incorporated in the secretary's report of the April meeting of the Chicago Section.

The suggestions which I offered to the committee may be arranged under three heads.

First. Publication of vacancies. - There should be established in the Bulletin a special department devoted to the announcement of vacancies. The administrative heads of all colleges and universities should be informed of the existence of this department and should be requested to avail themselves of it. The announcements should be as explicit as possible on the items of title, salary, grade and amount of work, probable date of appointment, address to which applications should be sent, date after which no applications will be considered, whether a specialist is desired or preferred, and if so in what special subject. If any of these items are subject to any uncertainty - if, for instance, as is often the case, an institution is not willing to announce a definite sum as salary because it would be willing to pay widely different salaries according to 
the exigencies of the case - the vacancy and its general character should nevertheless be announced.

Second. The filling of major positions. - A major position shall be defined as one to which is attached a salary of $\$ 2,000$ a year or more. It seems to me that the following plan might serve as a basis for discussion: If an institution desires the services of the Society in making a major mathematical appointment, it should send a request to the secretary describing as closely as possible the nature of the position to be filled and the kind of person desired. The secretary should acknowledge the request and receive assurance from the institution that it is willing to bear the expenses of the nominating committee, which expenses would in most cases be very small. Having received this assurance, the secretary should inform every member of the Council of the Society, requesting him to make out and send to the secretary before a specified date a list of six names (members or non-members of the Society) in order of preference, these to stand as his nominations for the nominating committee. Upon the specified day the secretary should tabulate the votes. The person receiving the highest number of votes should be appointed as chairman, and the two following him in the number of votes should be named as members of the nominating committee. It should be provided, however, that no two men employed in the same institution should be members of the committee. All ties, whether for chairmanship or membership, should be decided by the secretary. If two or more men from the same institution are voted into the same committee, the secretary should declare elected that one with the larger number of votes, or in case of a tie cast his own vote so as to decide for one of them, and then proceed to complete the committee from those next lower on the list.

If any person so elected to membership in a nominating committee is unable or unwilling to serve, the committee should be completed by election of the person next below him in the total number of votes. Acceptance of membership on the committee should imply renunciation on the part of the person accepting of any intention on his part of being himself a candidate for the position under consideration.

As soon as the committee has been finally constituted, the fact should be announced and the names of the members published in the Bulletrin. This should be coupled with a re- 
quest to all applicants to forward their applications, a list of their publications and other documents to the chairman, and as far as possible also to the other members of the committee.

It should be the duty of the committee of three elected in this way to consider and weigh carefully the claims of all applicants. But beyond this, it should in all cases survey the entire field and select three or more men who, according to its opinion, would be the best available persons for filling the position under consideration. It should arrange these men in order of preference, giving a brief discussion of the reasons for its decision. The possibility of bracketing two or three men of apparently equal merit should not be excluded however. The report of the committee should then be forwarded to the institution concerned, for any action which it may choose to take. The list of names recommended by the committee should also be published in the BuLLETIN in alphabetic order.

Most of the work of the committee could be done by correspondence. In many cases, however, it would be necessary, and it would always be desirable, for the committee to have an opportunity for oral discussion. It is not likely that an institution willing to take advantage of this plan would object to the expenses arising from this. I merely suggest, however, the possibility that a committee member living at a great distance might, with the approval of the President of the Society, appoint and instruct a substitute to take his place in the oral discussion. It would not be impossible to divide the country into regions and insist upon all members of a nominating committee being residents of one such region. But this plan would give rise to some very serious difficulties and grave objections.

Third. The filling of minor positions. - A minor position is defined as one worth less than $\$ 2,000$ a year. I can see little prospect of success in any attempt on the part of the Society to assist in making such appointments, on account of the large number of such positions, and the great amount of work and expense that would be involved. The suggestion which has been made of requiring a small fee of applicants and of employing a clerk to look after the matter would defeat our main object of giving expert advice on such appointments. We might perhaps think of a standing committee of the Council appointed for a year, to meet upon the days assigned to meetings of the Society, whose duty it would be to make recommendations of this character, if the material in each case were 
properly collected and sifted beforehand by an intelligent clerical assistant. It seems quite likely, however, that the careful filling of major positions would do away with any great necessity of reform in the methods of filling minor positions.

\section{PICARD'S ALGEBRAIC FUNCTIONS OF TWO VARIABLES.}

Théorie des Fonctions algébriques de deux Variables indépendantes.

Par Émile Picard, Membre de l'Institute, Professeur à

l'Université de Paris, et Georges Simart, Capitaine de

Frégate, Répétiteur à l'Ecole Polytechnique. Tome II.

Paris, Gauthier-Villars, 1906. 8 vo, v +528 pp.

As the general scope of this great work has been explained and discussed in a very full review of volume I,* it only remains to give an idea of the large amount of additional material contained in the second volume, which is more than twice the size of the first.

Three principal objects are aimed at. The first is to present a systematic account of the theory of algebraic surfaces as developed by the Italian mathematicians. This theory deals chiefly with systems of curves on any given surface and certain numerical invariants connected with them. The other objects. of the book have in view the transcendental side of the theory and deal with two of its main problems, namely, (1) the theory of the double integrals of the second kind, and (2) the integrals of total differentials of the third kind.

The work cannot be regarded as a treatise, since the subject matter with which it deals is still in a formative state and not yet sufficiently matured to admit of such a treatment. Its leading aim is rather to present in an accessible and connected form the numerous investigations of Professor Picard in this field. It accordingly consists in large part of reprints of memoirs and notes previously published in various journals together with such changes and additions as are needed to unite them into a systematic whole. A number of other notes relating to the subject, but not bearing directly on the three problems just mentioned, are collected together in an appendix of twenty pages. An additional note of about forty pages entitled "Sur

* By Mr. A. Berry in this Bulletin, 2d series, vol. 5 (June, 1899), pp. 438-451. 